\title{
Idiopathic pulmonary fibrosis fibroblasts migrate and proliferate to CC chemokine
} ligand 21

\author{
E.M. Pierce*, K. Carpenter*, C. Jakubzick*, S.L. Kunkel*, H. Evanoff*, K.R. Flaherty”, \\ F.J. Martinez ${ }^{\#}$, G.B. Toews ${ }^{\#}$ and C.M. Hogaboam*
}

ABSTRACT: Idiopathic pulmonary fibrosis (IPF)/usual interstitial pneumonia (UIP) is the severest form of idiopathic interstitial pneumonia for which therapeutic targets are needed. Surgical lung biopsy specimens from IPF/UIP patients exhibit focal expression of CC chemokine receptor (CCR) 7, but the identity of these CCR7-positive cells is unknown. The purpose of the present study was to examine the functional and signalling significance of CCR7 expression of primary fibroblasts grown from IPF/UIP and normal surgical lung biopsy specimens.

Primary fibroblasts were cultured from surgical lung biopsy specimens from IPF/UIP and normal patients. Fibroblasts treated with or without CC chemokine ligand $(C C L) 21$ were analysed for functional, transcriptional and proteomic differences using immunocytochemical analysis, gene arrays, Taqman real-time PCR, and migration, proliferation and Western blot assays.

CCR7 was expressed by IPF/UIP fibroblasts, but not normal fibroblasts. IPF/UIP fibroblasts, but not normal fibroblasts, showed significant migratory and proliferative responses when exposed to CCL21, which were inhibited by pertussis toxin or neutralising antibodies to CCR7. Exposure of IPF/UIP fibroblasts to CCL21 altered the phosphorylation status of mitogen-activated protein kinase kinase 1/2, extracellular signal-regulated kinase $1 / 2$ and ribosomal $\mathrm{S} 6$ kinase (90 kDa) in these cells; this was abrogated by pertussis toxin or CCR7-specific small interfering RNA.

Together, these data demonstrate that CC chemokine ligand 21 modulates the functional properties of idiopathic pulmonary fibrosis/usual interstitial pneumonia fibroblasts, but not normal fibroblasts.

KEYWORDS: CC chemokine ligand 21, CC chemokine receptor 7, chemokine, idiopathic interstitial pneumonia, mitogen-activated protein kinase, pulmonary

diopathic pulmonary fibrosis (IPF) with a usual interstitial pneumonia (UIP) histological pattern is the severest form of idiopathic interstitial pneumonia (IIP) [1]. IPF/UIP targets elderly males, and median survival is $\sim 3$ yrs from diagnosis [2, 3], indicating that present treatments are unsatisfactory [4]. IPF/UIP is driven by highly synthetic and proliferative cells resident and/or recruited to the lung, whose fibroproliferative activity leads to excessive deposition of collagen in interstitial tissue, leading to remodelling and ultimately impeding oxygen exchange. Key diagnostic histological features of IPF/UIP include temporal heterogeneity, with normal looking lung tissue disrupted by dense scarring and fibroblastic foci [5] Currently, the only successful treatment for IPF/ UIP is lung transplantation; thus discovery of a therapeutic target is urgently needed for these patients. Recent efforts to find new targets focused on altered transcript and protein expression in IPF/UIP lung biopsy samples [6, 7] and primary fibroblasts derived from lung biopsy specimens $[8,9]$.

One group of transcripts and corresponding proteins of interest are chemotactic cytokines (chemokines) [10]. Chemokines are small, soluble, membrane-bound proteins categorised on the basis of cysteines in their N-terminus. These proteins signal through G-protein-coupled receptors (GPCRs) on the cell surface [11] and affect a number of cellular functions, including migration, proliferation and adhesion. Recent examination of chemokine receptor transcript and protein expression in surgical lung biopsy (SLB) specimens from IIP and normal patients revealed a strong focal and diffuse interstitial pattern of CC
AFFILIATIONS

*Dept of Pathology, and

\#Division of Pulmonary and Critical Care Medicine, Dept of Internal Medicine, University of Michigan Medical School, Ann Arbor, MI, USA

CORRESPONDENCE

C.M. Hogaboam

Immunology programme, Dept of Pathology

University of Michigan Medical

School

Room 4057

BSRB

109 Zina Pitcher Place

Ann Arbor Ml

48109-0602

USA

Fax: 17349367996

E-mail: Hogaboam@med.umich.edu

Received:

September 192006

Accepted after revision:

February 092007

SUPPORT STATEMENT

C.M. Hogaboam, S.L. Kunkel, K.R

Flaherty, F.J. Martinez and G.B.

Toews were supported by a grant (P50 HL56402) from the National

Heart, Lung and Blood Institute

(Bethesda, MD, USA).

STATEMENT OF INTEREST

Statements of interest for S.L. Kunkel and F.J. Martinez can be found at www.erj.ersjournals.com/misc/ statements.shtml

European Respiratory Journal Print ISSN 0903-1936

Online ISSN 1399-3003 
chemokine receptor (CCR) 7 expression in IPF/UIP SLB specimens, which was absent in normal SLB specimens [12]. CCR7 is expressed on immune cells (dendritic and T-cells [13]), collagen-producing cells of haematopoietic origin (fibrocytes $[14,15])$ and neoplastic cells of breast origin [16]; however, CCR7 expression in IIP SLB specimens does not correlate with markers characterising these cells [12]. Whole lung transcript levels of the CCR7 ligands, CC chemokine ligand (CCL) 19 and CCL21 were high in all SLB specimens examined, but protein levels did not differ between IIP and normal biopsy specimens [12].

Given the interstitial expression of CCR7 in IIP SLB specimens, it was hypothesised that this chemokine receptor may be expressed and functionally active in SLB-derived primary fibroblasts. In the present study, migratory and proliferative activities were observed in IPF/UIP, but not normal fibroblasts exposed to CCL21. IPF/UIP fibroblast exposure to CCL21 led to altered phosphorylation of proteins associated with the extracellular signal-regulated kinase (ERK) 1/2 signalling pathway, which was blocked by pertussis toxin (PTX) or CCR7 small interfering RNA (siRNA). Thus these data demonstrate that IPF/UIP fibroblasts are responsive to CCR7-dependent activation, making CCR7 an attractive target in IPF/UIP. Some of the results of these studies have been reported previously [17].

\section{MATERIALS AND METHODS}

\section{Patients}

The Institutional Review Board of the University of Michigan Medical School (Ann Arbor, MI, USA) approved the present study. All patients underwent clinical evaluation, including chest radiography, lung function measurements and thinsection computed tomography, before undergoing fibreoptic bronchoscopy as previously described [12].

\section{Fibroblast isolation and culture}

Fibroblasts were mechanically dissociated and cultured from histologically proven IPF/UIP or histologically normal SLB specimens as previously described [18]. Briefly, SLB specimens were mechanically dispersed into $150 \mathrm{~cm}^{3}$ flasks with Dulbecco's modified Eagle medium (DMEM) supplemented with $15 \%$ foetal bovine serum (FBS), penicillin $\left(100 \mathrm{U} \cdot \mathrm{mL}^{-1}\right)$, streptomycin $\left(100 \mu \mathrm{g} \cdot \mathrm{mL}^{-1}\right)$ and Fungizone $\left(0.25 \mu \mathrm{g} \cdot \mathrm{mL}^{-1}\right)$. Adherent cells were grown to confluence at $37^{\circ} \mathrm{C}$ under $5 \%$ carbon dioxide and passaged six times before splitting and plating for experiments. Fibroblasts were used for experiments from the 7 th to the 11th passage.

\section{Protein collection and RNA extraction}

Primary fibroblasts were plated in 12-well tissue culture plates at a density of $2.5 \times 10^{5}$ cells $\cdot \mathrm{mL}^{-1}$. After washing, $500 \mu \mathrm{L}$ DMEM containing $0.5 \%$ FBS (DMEM-FBS) alone or in combination with $10 \mathrm{ng} \cdot \mathrm{mL}^{-1}$ recombinant CCL19 or CCL21 was added to quadruplicate wells for $24 \mathrm{~h}$. Cell-free supernatants were collected for soluble protein content analysis. Trizol $(250 \mu \mathrm{L})$ was added to each well and the RNA extracted according to the manufacturer's directions (Invitrogen, Carlsbad, CA, USA).

\section{Gene array}

Human CCR7, CCL19 and CCL21 gene expression were analysed using a specific chemokine and chemokine receptor gene array from SuperArray (Carlsbad).

\section{Taqman analysis}

CCR7 and reduced glyceraldehye-3-phosphate dehydrogenase (GAPDH) expression were analysed by real-time (RT) quantitative RT-PCR, using a 7500 RT-PCR System (Applied Biosystems, Foster City, CA, USA), as previously described [19]. All antibodies and probes were purchased from Applied Biosystems. CCR7 expression was normalised to that of GAPDH before the degree of change in expression was calculated.

\section{Immunocytochemistry}

Human CCR7 expression was analysed immunocytochemically, using a horseradish peroxidase (HRP)-aminoethyl carbazole cell and tissue staining kit according to the manufacturer's instructions (R\&D Systems, Minneapolis, MN, USA).

\section{Fibroblast migration assay}

Primary IPF/UIP and normal fibroblasts were added to $8-\mu \mathrm{m}$ Transwell inserts in 6-well cell culture plates in the presence or absence of $10 \mathrm{ng} \cdot \mathrm{mL}^{-1}$ CCL19 or CCL21 for $24 \mathrm{~h}$. Migrated fibroblasts in the bottom well were fixed, stained with haematoxylin and counted. In order to test for receptor or ligand specificity, $5 \mu \mathrm{g} \cdot \mathrm{mL}^{-1}$ anti-human CCR7, CCL19 or CCL21 antibodies were added to each well. As a control, $5 \mu \mathrm{g} \cdot \mathrm{mL}^{-1}$ immunoglobulin (Ig)G or $10 \mu \mathrm{L}$ PBS were added.

\section{Proliferation assay}

The proliferative ability of the fibroblasts was assessed in 24well tissue culture plates, using $\left[{ }^{3} \mathrm{H}\right]$ thymidine incorporation, as previously described [9].

\section{Bioplex protein assay}

Cell-free supernatants were analysed for human RANTES (regulated on activation, normal T-cell expressed and secreted)/CCL5, interferon (IFN)- $\alpha$, eotaxin, monocyte chemoattractant protein-1 (CCL2), platelet-derived growth factor-B, growth-related oncogene- $\alpha / C X C$ chemokine ligand (CXCL) 1 , IFN- $\gamma$-inducible protein 10 (CXCL10) and interleukin-8 using an extracellular antibody kit according to the manufacturer's instructions (Invitrogen), with a Bio-Rad Luminex Bio-Plex 200 System (Bio-Rad, Hercules, CA, USA).

\section{Western blot analysis}

Fibroblasts were starved for $24 \mathrm{~h}$ in serum-free DMEM and then treated with DMEM-FBS alone or in combination with $10 \mathrm{ng} \cdot \mathrm{mL}^{-1}$ recombinant CCL19 or CCL21 for various times. Other fibroblast cultures were pre-treated with $200 \mathrm{ng} \cdot \mathrm{mL}^{-1}$ PTX or transfected with $50 \mathrm{nM}$ CCR7-specific siRNA prior to serum deprivation and treatment. The fibroblasts were lysed in $500 \mu \mathrm{L}$ ice-cold lysis buffer consisting of $1 \%$ Triton X-100, $50 \mathrm{mM}$ sodium fluoride, $2 \mathrm{mM}$ ethylenediamine tetra-acetic acid (ethylenediamine tetraacetic acid), $200 \mu \mathrm{M}$ sodium orthovanadate, $5 \mu \mathrm{g} \cdot \mathrm{mL}^{-1}$ pepstatin, $5 \mu \mathrm{g} \cdot \mathrm{mL}^{-1}$ leupeptin and $100 \mathrm{nM}$ calyculin in PBS (pH 7.4). Total protein content was determined by Bradford assay. Samples containing $20 \mu \mathrm{g}$ total 
protein were resolved, transferred and blocked as previously reported [20]. The membranes were blotted for primary phospho-antibodies, stripped (Restore ${ }^{\mathrm{TM}}$ Stripping Buffer; Pierce, Rockford, IL, USA), washed and re-blotted for GAPDH, a loading control. The antibodies used in the Western analysis included monoclonal anti-human CCR7 antibody (R\&D Systems), phospho-antibodies directed against p44/p42 mitogen-activated protein kinase (MAPK), MAPK kinase 1/2, ribosomal S6 kinase (90 kDa; p90RSK), stressactivated protein kinase (SAPK)/ERK kinase 1/MAPK kinase 4, SAPK/c-Jun N-terminal kinase (JNK), c-Jun II, p38 MAPK and MAPK kinase 3/MAPK kinase 6 (all from Cell Signaling, Danvers, MA, USA), anti-GAPDH and a rabbit polyclonal directed against smooth muscle $\alpha$-actin ( $\alpha$-SMA; Abcam, Cambridge, MA, USA). The secondary antibodies used were HRP-conjugated anti-rabbit, anti-mouse and anti-biotin antibodies (Cell Signaling).

\section{Transfection of SiRNA}

siRNAs targeting CCR7 were created using the Qiagen custom synthesis site [21]. The effectiveness of two siRNA candidates was tested through transfection with Lipofectamine 2000 (Invitrogen) into IPF/UIP lung fibroblasts. The more efficient siRNA (AGCGGACATCAGCTGGTCAA) was transfected as previously described [22].

\section{Statistical analysis}

All results are expressed as mean \pm SEM. One-way ANOVA and Tukey-Kramer multiple comparisons tests were used to detect differences between IPF/UIP and normal groups. Significance was set at a p-value of $<0.05$.

\section{RESULTS}

\section{CCR7, CCL19 and CCL21 expression in normal and IPF/UIP fibroblasts}

RNA from three normal and three IPF/UIP SLB-derived fibroblast lines was analysed using a specific human chemokine and chemokine receptor SuperArray. This analysis revealed that CCR7, CCL19 and CCL21 were present in both groups (fig. 1), but that CCR7 expression was significantly higher in IPF/UIP lines compared with normal lines (fig. 1a). Further analysis of gene expression using Taqman RT-PCR confirmed the presence of transcripts of CCR7, CCL19 and CCL21 in all fibroblast lines used in the present study (data not shown). Thus these data demonstrate that CCR7, CCL19 and CCL21 gene transcripts were present in both normal and IPF/ UIP fibroblasts derived from SLB material.

\section{CCR7 expression in cultured normal and IPF/UIP fibroblasts}

A previously published study revealed that nearly $100 \%$ of IPF/UIP SLB specimens exhibited focal and diffuse CCR7 protein expression in interstitial areas [12]. Focal areas of CCR7 appeared to coincide with histologically distinct fibroblastic foci [12]. In order to determine whether or not primary fibroblasts grown from normal and IPF/UIP SLB specimens expressed CCR7, immunocytochemical staining for CCR7 was performed. Nearly $100 \%$ of IPF/UIP fibroblasts in culture were strongly positive for CCR7, whereas normal fibroblasts expressed little or no CCR7 (fig. 2).
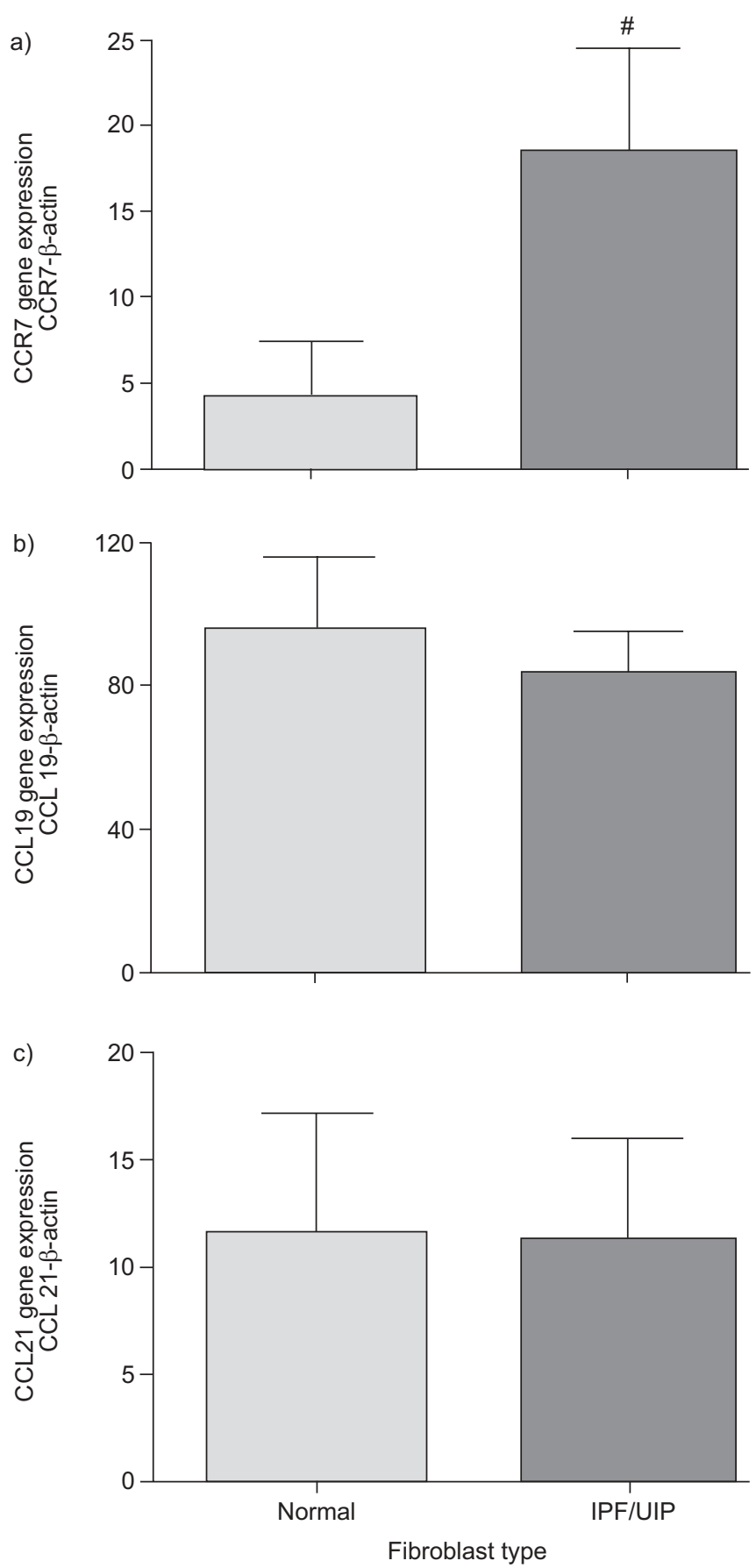

FIGURE 1. - SuperArray analysis of a) CC chemokine receptor (CCR) 7, b) CC chemokine ligand (CCL) 19 and c) CCL21 gene expression normalised to that of $\beta$ actin in primary normal and idiopathic pulmonary fibrosis (IPF)/usual interstitial pneumonia (UIP) fibroblasts derived from surgical lung biopsy material. Data are presented as mean \pm SEM ( $n=3$ for both fibroblast types). ${ }^{*}: p<0.0431$.

CCL21-directed migration of normal and IPF/UIP fibroblasts CCR7 expression is upregulated on mature dendritic cells, allowing migration to lymph nodes for immune activation [23]. On certain breast tumour [16] and melanoma cells [24], CCL21 activation of CCR7 is important in metastasis. In the present study, both CCL19 (data not shown) and CCL21 (fig. 3a) promoted migration of IPF/UIP but not normal fibroblasts, 


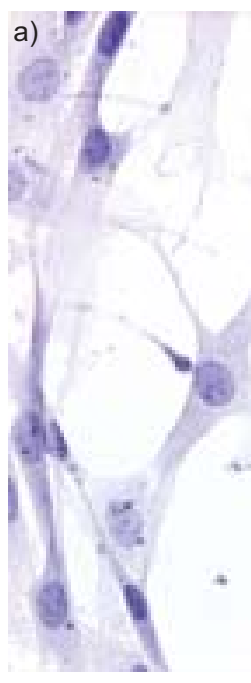

c)

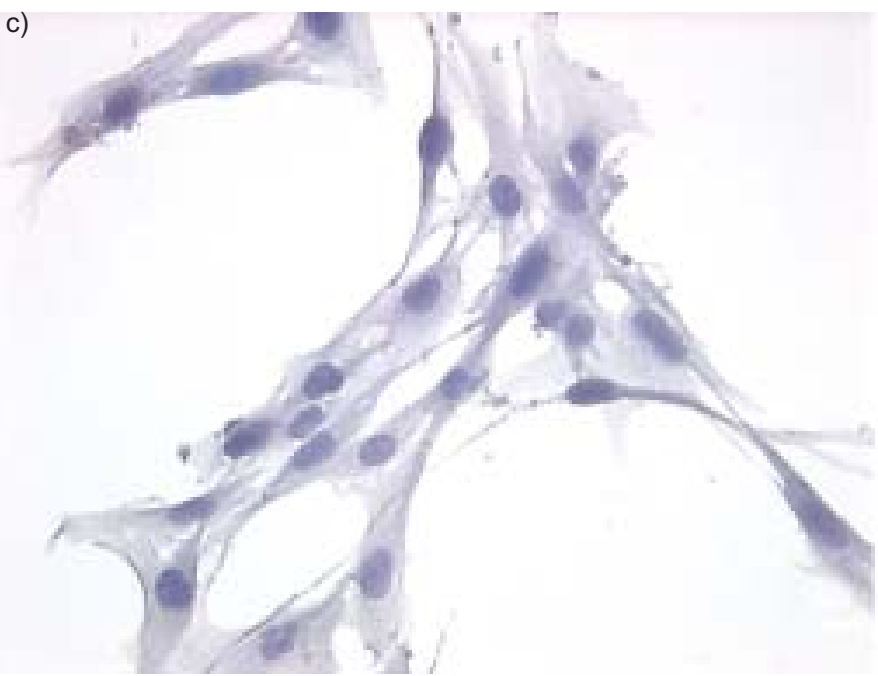

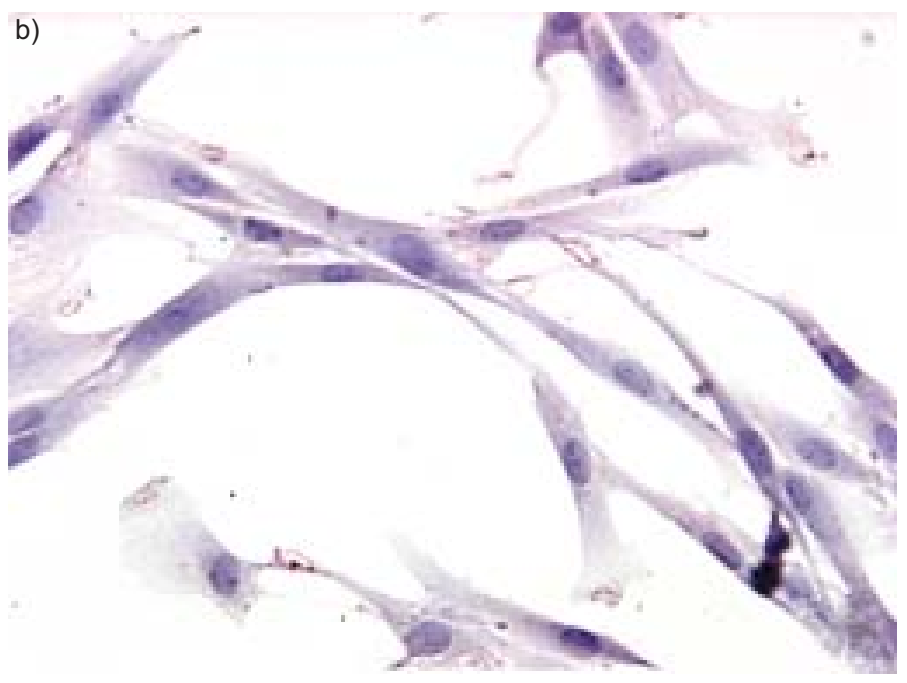

d)

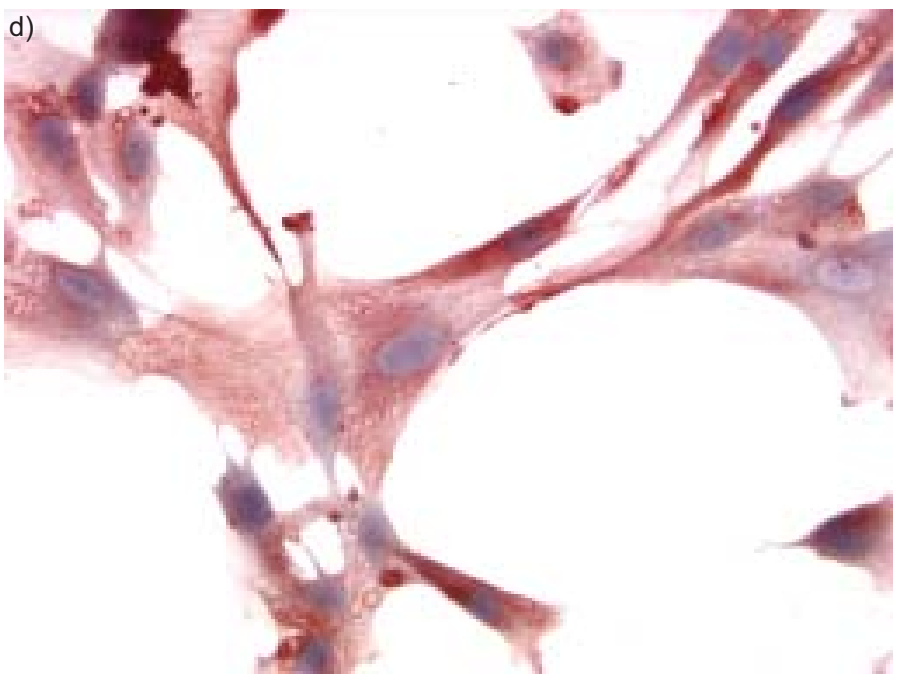

FIGURE 2. - Representative immunocytochemical analysis of human CC chemokine receptor (CCR) 7 in primary fibroblasts derived from: a, b) normal and c, d) idiopathic pulmonary fibrosis (IPF)/usual interstitial pneumonia (UIP) surgical lung biopsy specimens. a, c) Isotype control staining and b, d) CCR7 immunoreactivity (red stain), which is low in primary normal fibroblasts (b) but high in primary IPF/UIP fibroblasts (d).

with CCL21 enhancing migration approximately seven-fold compared with that observed in IPF/UIP fibroblasts exposed to DMEM alone (fig. 3a). In order to verify the CCR7 dependence, $5 \mu \mathrm{g} \cdot \mathrm{mL}^{-1} \mathrm{IgG}$, anti-human CCR7 or anti-human CCL21 antibody was added to triplicate wells. Although IgG did not alter the migration of IPF/UIP fibroblasts, anti-CCR7 or anti-CCL21 antibodies significantly inhibited the migratory response of these fibroblasts (fig. 3b). Pre-treating IPF/UIP fibroblasts with $200 \mathrm{ng} \cdot \mathrm{mL}^{-1}$ PTX also inhibited CCL21induced migration (data not shown). Together, these data indicate that CCR7 activation promotes the migration of IPF/ UIP but not normal fibroblasts.

\section{CCR7 activation and IPF/UIP fibroblast proliferation}

$\mathrm{IPF} / \mathrm{UIP}$ is characterised by severe alveolar and interstitial scarring of the lung due, in part, to extensive fibroproliferation. In the present study, all three IPF/UIP fibroblast lines exhibited an enhanced baseline (i.e. DMEM alone) proliferation rate, approximately three-fold higher than the normal fibroblasts lines studied (figs $3 \mathrm{c}$ and $\mathrm{d}$ ). In addition, $10 \mathrm{ng} \cdot \mathrm{mL}^{-1}$
CCL21, but not CCL19 (data not shown), significantly increased the proliferative properties of all IPF/UIP fibroblast lines compared with cultures exposed to DMEM alone (fig. 3c). The proliferative properties of normal fibroblasts were not altered by the presence of either CCL19 (data not shown) or CCL21 (fig. 3d).

\section{CCR7 activation and CCL5 generation by primary IPF/UIP fibroblasts}

Previous studies have shown that chemokines may drive the expression of other chemokines in various cell types. For example, addition of CCL5 to IPF/UIP fibroblast cultures significantly enhanced expression of CCL7, a putative biomarker in IPF/UIP [8]. In order to determine whether CCR7 activation via CCL21 altered the chemokine-generating properties of IPF/UIP and normal fibroblasts, both groups of fibroblasts were exposed to CCL21 for $24 \mathrm{~h}$ prior to soluble multiplex protein analysis. As shown in figure 4a, CCL5 was present in both IPF/UIP and normal fibroblast cultures, and CCL21 significantly increased CCL5 levels in IPF/UIP, but not 


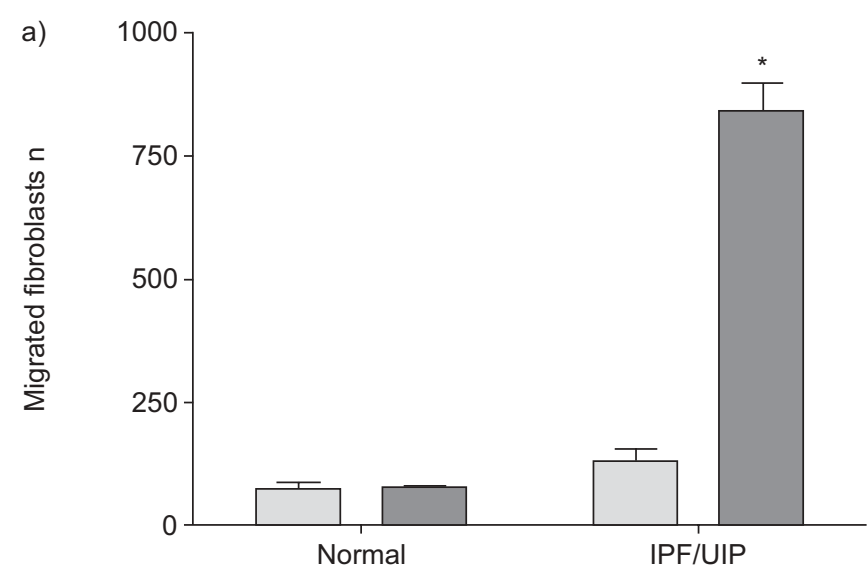

Fibroblast type

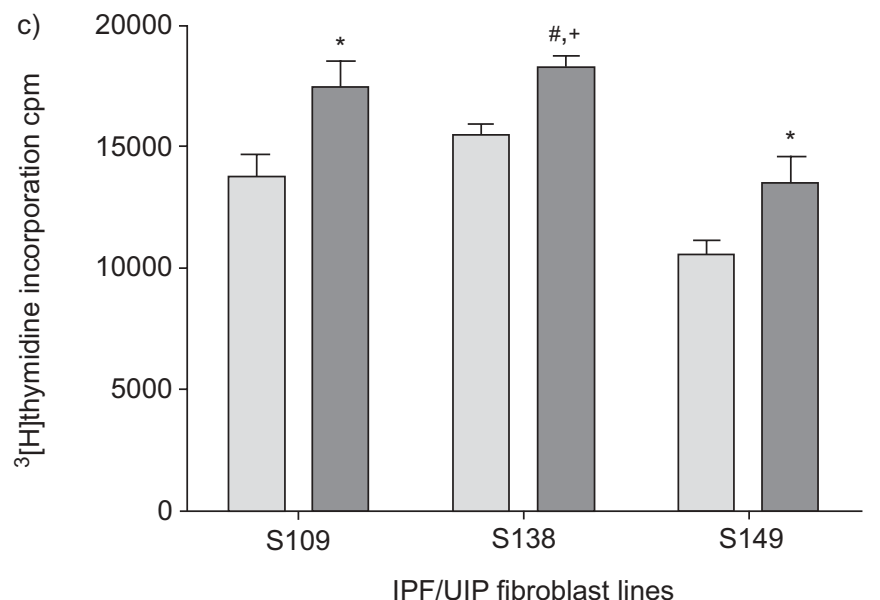

b)

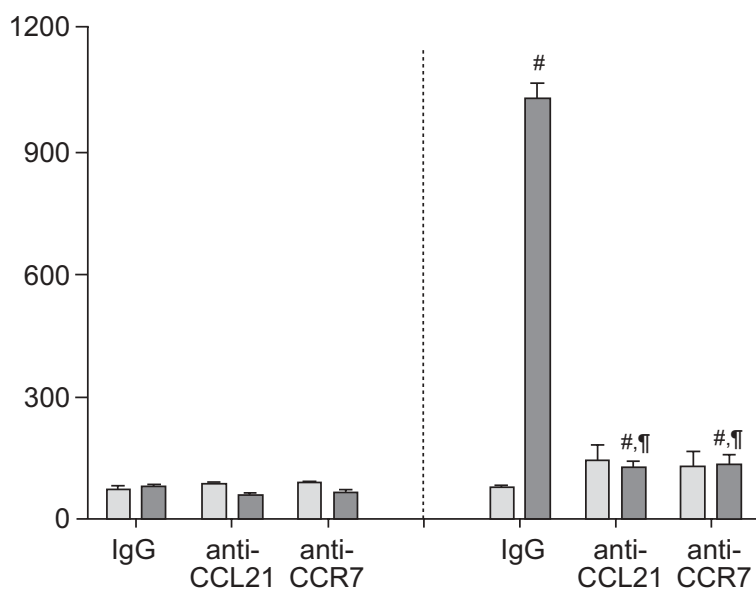

Fibroblast treatment

d)

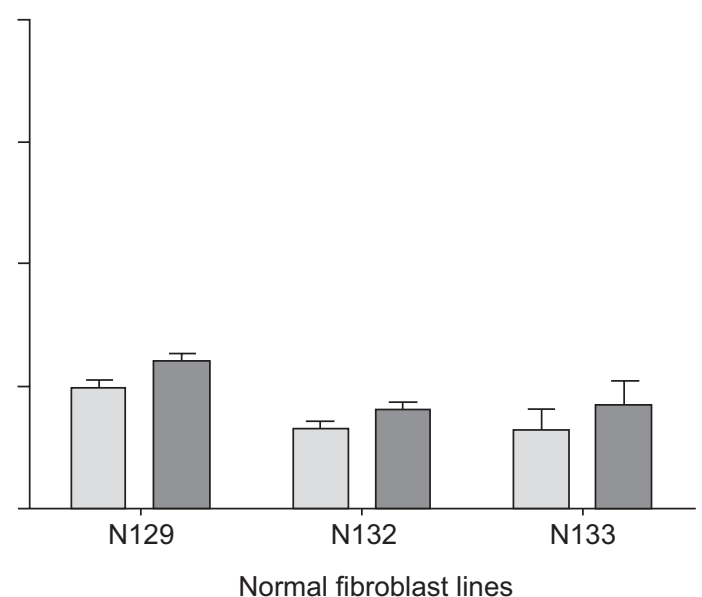

FIGURE 3. - Functional assay of primary normal and idiopathic pulmonary fibrosis (IPF)/usual interstitial pneumonia (UIP) fibroblasts cultured from surgical lung biopsy material. Fibroblast migration in Transwells in normal and IPF/UIP fibroblasts in: a) the absence of antibodies, and b) the presence of immunoglobulin (Ig)G or anti-human CC chemokine ligand (CCL) 21 or CC chemokine receptor (CCR) 7 antibodies (all $10 \mu \mathrm{g} \cdot$ well $^{-1}$; left-hand panel is normal, right-hand panel is IPF/UIP). Proliferation, as determined by $\left[{ }^{3} \mathrm{H}\right]$ thymidine incorporation of: c) primary IPF/UIP cell lines, and d) primary normal fibroblast cell lines. All experiments were performed in Dulbecco's modified Eagle medium alone $(\square)$ or in combination with $10 \mathrm{ng} \cdot \mathrm{mL}^{-1} \mathrm{CCL} 21$ ( $\square$ ). Data are presented as mean \pm SEM ( $\mathrm{n}=3$ for all fibroblast types). Migration through to the bottom of the Transell was increased in IPF/UIP but not normal fibroblasts (a). Addition of antibodies directed against CCR7 or CCL21, but not IgG, mitigated the CCL21-mediated increase in migration (b). Primary IPF/UIP fibroblasts (c) showed higher baseline proliferation than primary normal fibroblasts (d). Addition of CCL21 to primary IPF/UIP fibroblasts significantly increased proliferation in all three fibroblast lines (c), whereas it had no effect on primary normal fibroblasts (d). cpm: counts per minute. *: $p<0.05$ ${ }^{\#}: p<0.0001 ; ": p \leqslant 0.0001 ;{ }^{+}: p=0.0016$.

normal, fibroblasts. These data, together with those from previous studies, indicate that CCR7 activation enhances the chemokine synthetic capabilities of IPF/UIP fibroblasts.

\section{Effect of CCL21 on $\alpha$-SMA expression in primary IPF/UIP and normal fibroblasts}

$\alpha$-SMA is a protein marker for myofibroblasts, a highly synthetic fibroblast subtype [25]. Given the profound effects of CCL21 on the synthesis of chemokines by IPF/UIP fibroblasts, whether or not CCR7 ligands altered the expression of $\alpha$-SMA in these cells was addressed. Western blot analysis showed that IPF/UIP fibroblasts expressed higher levels of $\alpha$-SMA than normal fibroblasts (fig. $4 \mathrm{~b}$ ), consistent with the greater synthetic properties of IPF/UIP fibroblasts. However, $\alpha$-SMA expression was not affected by the presence of CCL21 (fig. 4b), suggesting that CCR7 activation was not a major stimulus for fibroblast differentiation into myofibroblasts.

\section{CCR7 activation by CCL21 and the p44/p42 ERK signalling pathway in IPF/UIP fibroblasts}

MAPK pathways are known to regulate many important cell functions. Each pathway has unique effects on the cell cycle, growth and migration, due, in part, to activation of each pathway by distinct stimuli, including growth factors, stress and inflammatory cytokines. Signalling cascades initiated by these stimuli involve sequential phosphorylation of a MAPK kinase kinase, a MAPK kinase and a MAPK. After phosphorylation, MAPKs enter the nucleus and activate one or several downstream transcription factors, leading to a biological response. In order to determine the effects of activated CCR7 


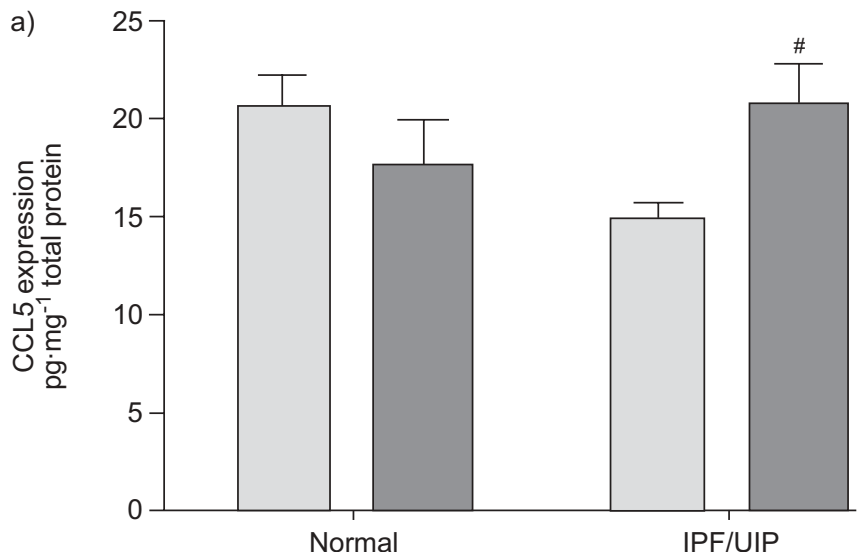

Fibroblast lines

b)

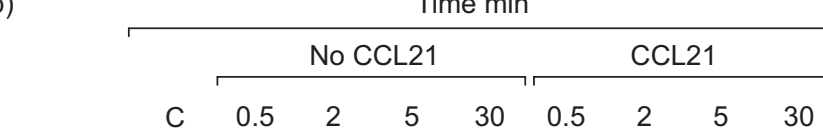

$\alpha-S M A$

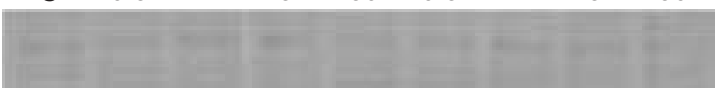

GAPDH

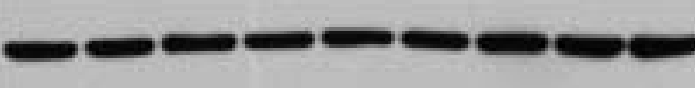

c)

\begin{tabular}{|c|c|c|c|c|c|c|c|c|}
\hline \multicolumn{9}{|c|}{ Time $\min$} \\
\hline \multirow[b]{2}{*}{ C } & & No & $\mathrm{L} 2$ & & & $\mathrm{CO}$ & & \\
\hline & 0.5 & 2 & 5 & 30 & 0.5 & 2 & 5 & 30 \\
\hline
\end{tabular}

$\alpha-S M A$

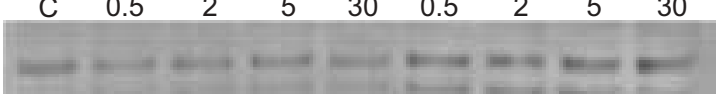

GAPDH

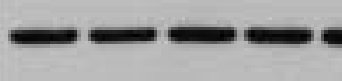

FIGURE 4. - Protein analysis in primary idiopathic pulmonary fibrosis (IPF)/ usual interstitial pneumonia (UIP) and normal fibroblasts cultured from surgical lung biopsy material. a) Bioplex analysis of human CC chemokine ligand (CCL) 5 levels in cell-free supernatants from normal and IPF/UIP fibroblasts cultured in the presence of Dulbecco's modified Eagle medium containing $0.5 \%$ foetal bovine serum (DMEM-FBS) alone ( $\square$ ) or in combination with $10 \mathrm{ng} \cdot \mathrm{mL}^{-1}$ CCL21 ( $\square$ ). Data are presented as mean \pm SEM ( $\mathrm{n}=3$ for both fibroblast types). There was a significant increase in CCL5 expression with the addition of CCL21. Western blot analysis of smooth muscle $\alpha$-actin ( $\alpha$-SMA) in whole cell lysates from: b) primary normal, and c) primary IPF/UIP fibroblasts starved for $24 \mathrm{~h}$ and then treated with DMEM-FBS alone or in combination with CCL21 $\left(10 \mathrm{ng} \cdot \mathrm{mL}^{-1}\right)$ for the indicated times (see Methods section). IPF/UIP fibroblasts expressed higher levels of $\alpha$-SMA than normal fibroblasts; however, these levels were not affected by addition of CCL21. Each blot is representative of three separate experiments. C: Untreated fibroblast control; GAPDH: reduced glyceraldehye-3-phosphate dehydrogenase. ${ }^{*}: p<0.0358$.

on MAPK pathways, untreated and CCL21-activated fibroblast-associated proteins were collected at $30 \mathrm{~s}$ and 2, 5 and $30 \mathrm{~min}$, and Western blots of the ERK 1/2, p38 and JNK MAPK pathways were analysed. Although no phosphorylation changes in signalling proteins were associated with the p38 and JNK pathways (data not shown), the ERK 1/2 pathway showed evidence of phosphorylation changes following CCL21 addition to IPF/UIP fibroblast cultures. Phosphorylation of murine leukaemia viral oncogene homologue 1 (c-Raf), the MAPK kinase kinase of this pathway (data not shown), was also not found. Figures 5-8 summarise the effects of CCL21 on ERK 1/2-dependent activation in normal and IPF/UIP fibroblasts.

\section{Phosphorylation of MAPK kinase $1 / 2$ in IPF/UIP fibroblasts following CCL21 exposure}

Resting (i.e. serum-starved) primary normal and IPF/UIP fibroblast lines did not exhibit constitutively activated MAPK kinase 1/2 (fig. 5a). Addition of DMEM-FBS alone to normal fibroblasts caused a time-dependent increase in phosphorylation of MAPK kinase $1 / 2$, which peaked at 5 min and was unchanged by the addition of $10 \mathrm{ng} \cdot \mathrm{mL}^{-1}$ CCL21 (fig. 5a). Although treatment with DMEM-FBS alone promoted similar time-dependent activation of MAPK kinase1/2 in IPF/UIP fibroblasts, addition of $10 \mathrm{ng} \cdot \mathrm{mL}^{-1}$ CCL21 resulted in an increase in phosphorylation at 2 and $5 \mathrm{~min}$, with phosphorylation returning to DMEM-FBS levels at $30 \mathrm{~min}$ (fig. 5a). Together, these data suggest accelerated activation of MAPK kinase 1/2 in IPF/UIP fibroblasts exposed to CCL21.

\section{CCL21 and ERK 1/2 phosphorylation in IPF/UIP fibroblasts}

Resting primary normal and IPF/UIP fibroblasts exhibited constitutive ERK 1/2 phosphorylation, but baseline activity appeared higher in normal fibroblasts compared with IPF/UIP fibroblasts (fig. 5b). Treatment of normal fibroblasts with DMEM-FBS alone resulted in peak ERK $1 / 2$ activation at $5 \mathrm{~min}$, and addition of $10 \mathrm{ng} \cdot \mathrm{mL}^{-1}$ CCL21 gave a similar pattern, with overall lower levels of ERK $1 / 2$ phosphorylation in these cultures (fig. 5b). IPF/UIP fibroblast cultures treated with DMEM-FBS alone produced a similar pattern of ERK 1/2 phosphorylation; however, the magnitude of activation was much higher than in normal fibroblasts. In IPF/UIP fibroblast cultures exposed to CCL21 and DMEM-FBS, there was a significant increase in phosphorylation at 2 min compared with IPF/UIP cultures exposed to DMEM-FBS alone (fig. 5b). Since constitutive ERK 1/2 phosphorylation was low in IPF/ UIP fibroblasts, phosphorylation levels following exposure to DMEM-FBS alone or in combination with $10 \mathrm{ng} \cdot \mathrm{mL}^{-1}$ CCL21 ranged 60-125-fold higher than that of resting IPF/UIP fibroblasts (fig. 5b).

\section{CCL21 and $90 \mathrm{kDa}$ ribosomal S6 kinase phosphorylation in IPF/UIP fibroblasts}

In myelopoiesis, p90RSK has been shown to be activated by CXCL12 [26]. The present study revealed that p90RSK (located downstream of ERK 1/2) was present in a phosphorylated state in resting normal and IPF/UIP fibroblasts (fig. 5c). Changes in activation of p90RSK were similar in normal fibroblast cultures regardless of the presence of CCL21. In contrast, the presence of CCL21 in IPF/UIP fibroblast cultures at all time points enhanced phosphorylation of this transcription factor $\sim 2.5$-fold compared with that observed in untreated cultures (fig. 5c). Together, these data indicate that CCR7 is an active receptor in IPF/UIP fibroblasts, and this receptor appears to signal, at least in part, via the ERK $1 / 2$ pathway. 
a)
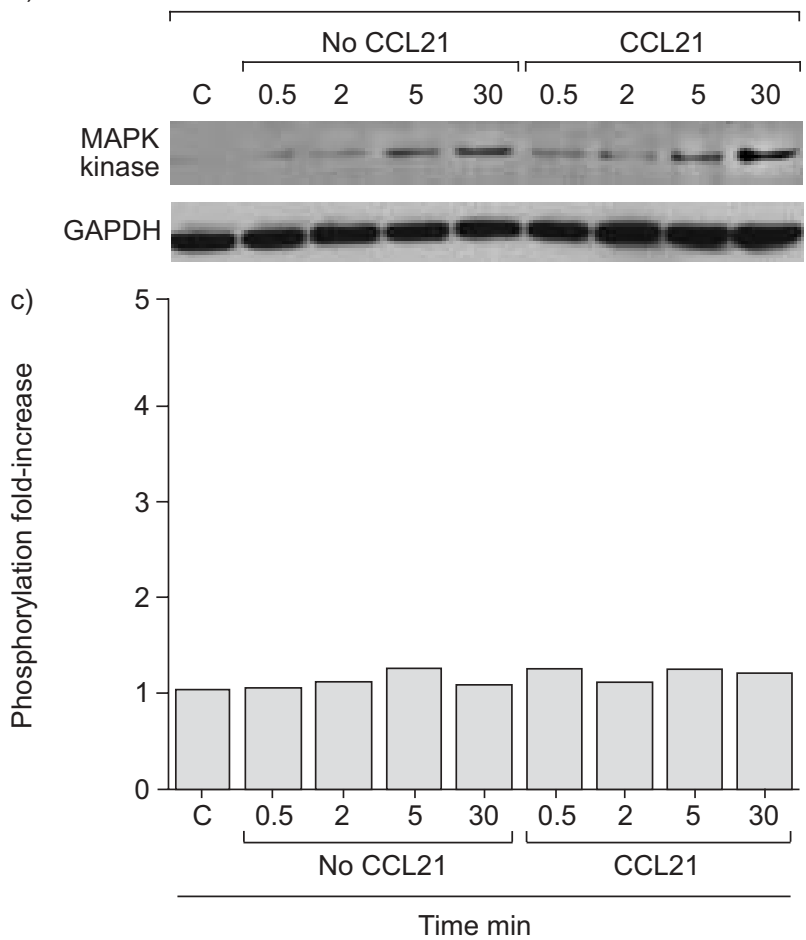

b)

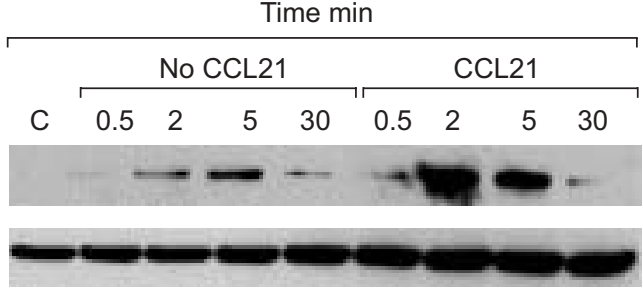

d)

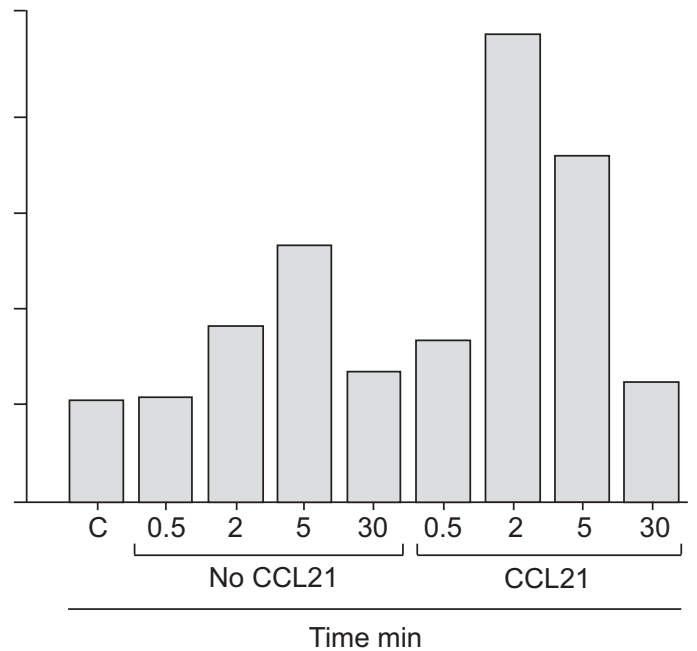

FIGURE 5. - Western Blot analysis of the phosphorylation of mitogen-activated protein kinase (MAPK) kinase 1/2 in: a and c) whole cell lysates of primary normal; and b and d) whole cell lysates of idiopathic pulmonary fibrosis/usual interstitial pneumonia fibroblasts starved for $24 \mathrm{~h}$ and then treated with Dulbecco's modified Eagle medium containing $0.5 \%$ foetal bovine serum alone or in combination with $10 \mathrm{ng} \cdot \mathrm{mL}^{-1} \mathrm{CC}$ chemokine ligand (CCL) 21 (see Methods section). a and b) Western blots; $\mathrm{c}$ and $\mathrm{d}$ ) increase in phosphorylation compared with untreated fibroblasts. Each photographic film was exposed for $30 \mathrm{~s}$. The degree of increase in phosphorylation was determined by normalisation to reduced glyceraldehye-3-phosphate dehydrogenase (GAPDH) levels and then comparison between treated and untreated fibroblasts. The results presented in this figure and figures 6 and 7 are representative of three separate experiments. C: untreated fibroblast control.

\section{G-protein inhibition with PTX or CCR7 gene silencing with siRNA and CCL21-mediated ERK 1/2 activation}

In order to confirm the role of CCR7 in IPF/UIP fibroblast activation, additional studies were undertaken to determine whether PTX (an inhibitory G-protein (Gi) and Go inhibitor [27]) or siRNA-mediated CCR7 gene silencing abolished the effects of CCL21 on ERK 1/2 activation. As shown in figure 8a, transfection with a specific CCR7 $\operatorname{siRN} A$ prior to treatment with DMEM-FBS reduced protein expression of this receptor by $\sim 70 \% 24 \mathrm{~h}$ after transfection. Inhibition of CCR7 protein expression persisted for the 30-min duration of the present studies. Neither a lamin-A/C-specific siRNA nor a random siRNA affected protein expression of CCR7 in IPF/UIP fibroblasts (fig. 8a). These data showed that CCR7 was successfully targeted in vitro using a specific siRNA. The presence of either PTX or a CCR7 siRNA in IPF/UIP fibroblast cultures reduced MAPK kinase 1/2, ERK $1 / 2$ and p90RSK phosphorylation to levels observed in cultures exposed to DMEM-FBS alone (fig. 8b). Taken together, these data show that CCL21-induced MAPK kinase 1/2, ERK 1/2 and p90RSK phosphorylation is dependent upon functional G-proteincoupled signalling events and CCR7.

\section{DISCUSSION}

Several studies have documented that primary human lung fibroblasts exhibit profibrotic activation in response to chemokines [28-31], of which they are a robust source [8, 29, 30]. The present study addressed the role of CCR7 expression by primary IPF/UIP fibroblasts derived from SLB specimens. In contrast to primary normal fibroblasts derived from normal margins of resected lung tumours, nearly $100 \%$ of fibroblasts cultured from histologically proven IPF/UIP SLB specimens expressed CCR7, a receptor once thought to be restricted to haematopoietic cells. Activation of CCR7, via CCL21 more than CCL19, promoted and/or significantly augmented the migration, proliferation and chemokine synthetic properties of IPF/ UIP fibroblasts. Exogenous CCL21, in a CCR7-dependent manner, activated the ERK $1 / 2$ MAPK pathway. Thus the present study suggests that IPF/UIP fibroblasts acquire the ability to respond to CCR7 ligands (abundantly expressed in the lung regardless of disease status [12]), and this responsiveness may have a major role in the excessive fibroproliferation that characterises IPF/UIP.

The presence of CCR7 in SLB-derived IPF/UIP but not normal fibroblasts raises the key question of the origin of the former fibroblasts. Certainly, it is now well appreciated that bone marrow-derived immune cells express this chemokine receptor and utilise it for immunosurveillance purposes under health and disease conditions [32]. However, functional CCR7 has also been found on bone marrow-derived fibrocytes [14], which may have a marked role in the perpetuation of 
a)

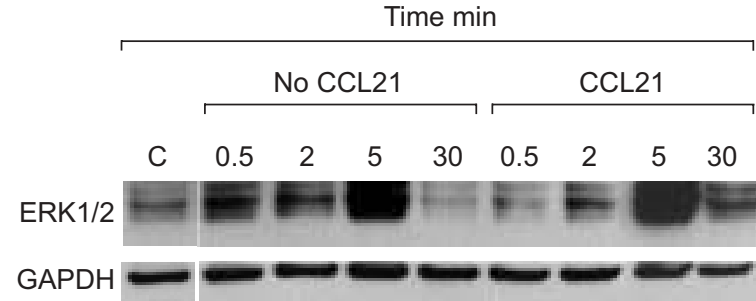

c)

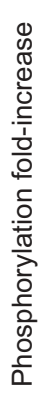

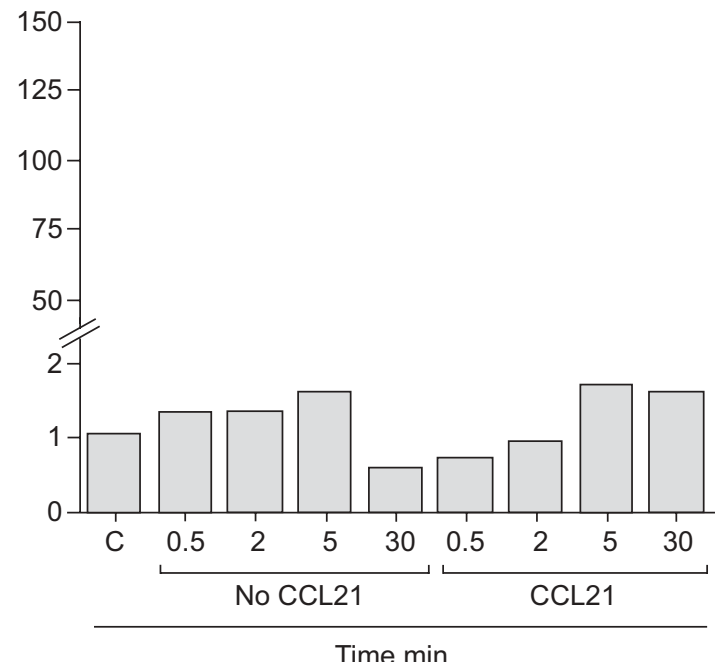

b)

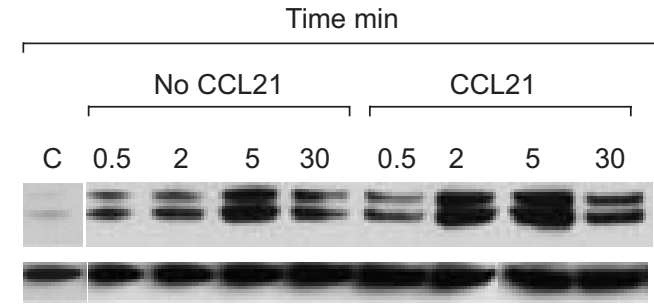

d)

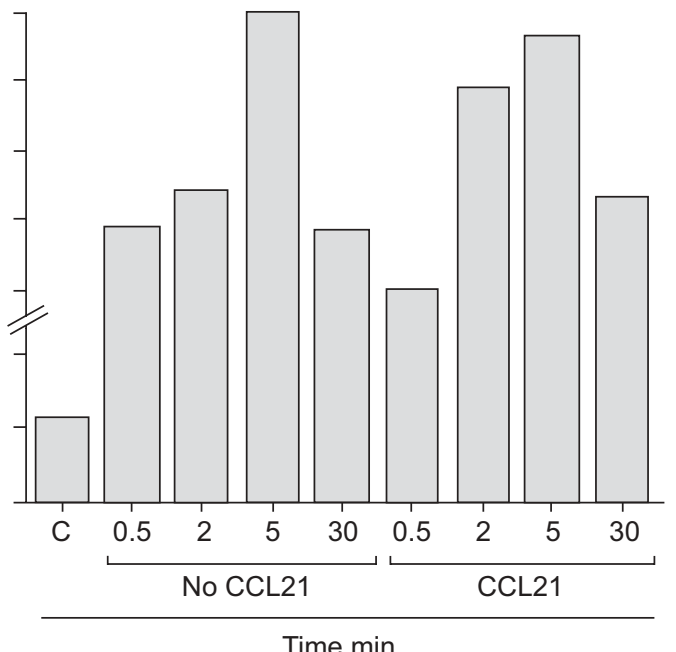

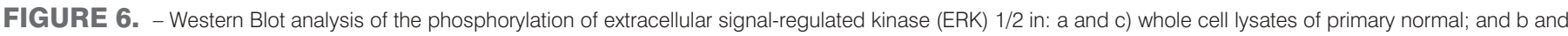

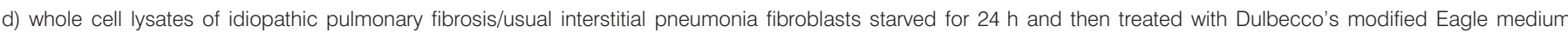
containing $0.5 \%$ foetal bovine serum alone or in combination with $10 \mathrm{ng} \cdot \mathrm{mL}^{-1} \mathrm{CC}$ chemokine ligand (CCL) 21 (see Methods section). a and b) Western blots; c and d)

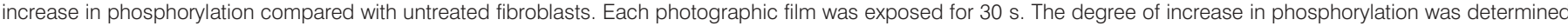

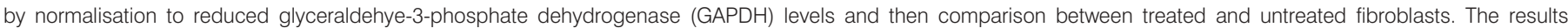
presented in this figure and figures 5 and 7 are representative of three separate experiments. C: untreated fibroblast control.

experimental pulmonary fibrosis [15]. Given these findings, it is conceivable that, unlike normal SLB-derived fibroblasts, the IPF/UIP SLB-derived fibroblasts studied herein were of bone marrow origin and, therefore, remained responsive to CCR7 ligands. Although the contribution of bone marrow cells to the lung fibrotic response in IPF cannot be ruled out, the IPF/UIP fibroblasts employed in the present study did not express any other fibrocyte markers previously described in the literature (i.e. CD34, CD45, CD86 and major histocompatibility complex II [14]), possibly due to loss of these markers as fibrocytes occupied the lung parenchyma after recruitment [33, 34]. Alternatively, the CCR7-positive fibroblasts studied herein may have been resident cells that obtained the ability to express functional CCR7 as a consequence of ongoing disease. In support of this hypothesis, it was found that both normal and IPF/UIP fibroblasts contained CCR7 transcripts. Furthermore, neoplastic transformation of breast and skin cells leads to their expression of CCR7, and CCL21 subsequently directs metastasis of these cells [24, 35]. A limitation of the present study lies in the fact that primary cultures of human fibroblasts, which may contain collagen-producing cells of various origins, were used. In order to address this limitation, ongoing studies are addressing CCR7-mediated changes in cloned versions of fibroblasts from various origins. However, these ongoing studies to address the origin of CCR7-positive
IPF/UIP fibroblasts depend upon identification of fibrocytespecific markers that persist as these cells mature into fibroblasts and/or myofibroblasts. It would also be interesting to determine which profibrotic signals facilitate the expression of CCR7 protein in normal fibroblasts.

Similar to other CCRs, CCR7 has two endogenous ligands, CCL19 and CCL21, which exhibit similar binding affinities and chemotactic potencies in T-cells [36]. However, studies suggest that these ligands signal distinctly due to their differential ability to desensitise CCR7 in immune cells, especially CCR7transfected cells $[37,38]$. In these studies, pre-treatment with CCL19 inhibited and reduced CCL19- and CCL21-induced proliferation, respectively, whereas pre-treatment with CCL21 had no effect on CCL19- or CCL21-induced proliferation [37, 38]. The precise mechanism of this selective desensitisation is unknown. In the present study, CCL19 was much less effective at activating CCR7-dependent effects (i.e. migration, proliferation and chemokine synthesis) in IPF/UIP fibroblasts than was CCL21. This differential response may be explained by receptor desensitisation to endogenous CCL19, found in greater abundance compared with the endogenous CCL21 in cultures of IPF/UIP fibroblasts (data not shown).

CCL21-mediated activation of CCR7 was limited to the ERK 1/2 MAPK pathway in IPF/UIP fibroblasts, as the p38 and JNK 
a)

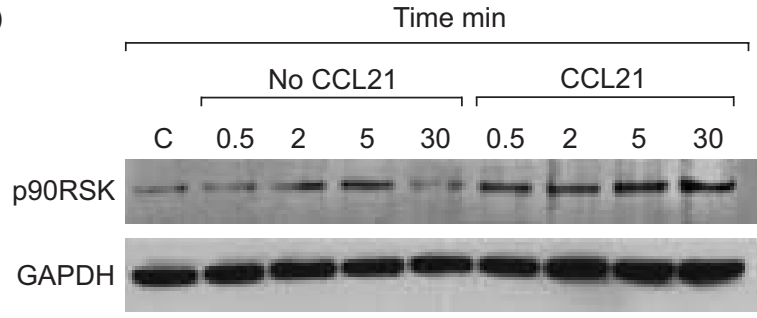

c)

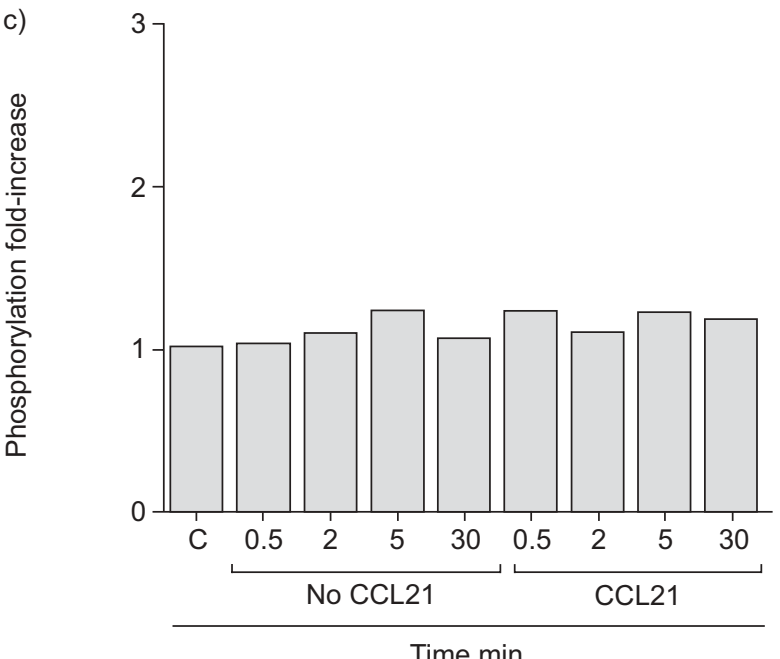

b)

\begin{tabular}{|c|c|c|c|c|c|c|c|c|}
\hline \multicolumn{9}{|c|}{ Time min } \\
\hline \multirow[b]{2}{*}{ C } & \multicolumn{4}{|c|}{ No CCL21 } & \multicolumn{4}{|c|}{ CCL21 } \\
\hline & 0.5 & 2 & 5 & 30 & 0.5 & 2 & 5 & 30 \\
\hline- & $\longrightarrow$ & - & - & - & $=$ & 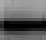 & & $=$ \\
\hline
\end{tabular}

d)

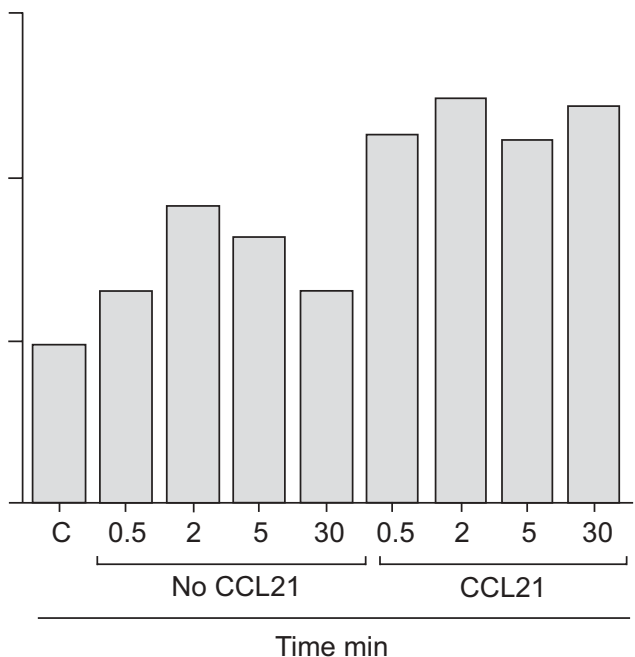

FIGURE 7. - Western Blot analysis of the phosphorylation of ribosomal S6 kinase (90 kDa; p90RSK) in: a and c) whole cell lysates of primary normal; and b and d) in whole cell lysates of idiopathic pulmonary fibrosis/usual interstitial pneumonia fibroblasts starved for $24 \mathrm{~h}$ and then treated with Dulbecco's modified Eagle medium containing $0.5 \%$ foetal bovine serum alone or in combination with $10 \mathrm{ng} \cdot \mathrm{mL}^{-1} \mathrm{CC}$ chemokine ligand (CCL) 21 (see Methods section). a and b) Western blots; $\mathrm{c}$ and d) increase in phosphorylation compared with untreated fibroblasts. Each photographic film was exposed for $30 \mathrm{~s}$. The degree of increase in phosphorylation was determined by normalisation to reduced glyceraldehye-3-phosphate dehydrogenase (GAPDH) levels and then comparison between treated and untreated fibroblasts. The results presented in this figure and figures 5 and 6 are representative of three separate experiments. C: untreated fibroblast control.

MAPK pathways were not activated by CCL21. ERK $1 / 2$ is important to cell proliferation and DNA synthesis, in part through its activation of p90RSK. In the absence of phosphorylated p90RSK, cells arrest and fail to leave the cell cycle [26]. This MAPK pathway is activated by mitogens, growth factors and GPCRs [39]. CCR7 is a GPCR, which requires $\mathrm{Gi}$ signalling for proper function. PTX is a specific inhibitor of the $\alpha$-subunit of the Gi/Go family and is known to inhibit GPCR function [40]. In the present study, it was observed that the enhanced phosphorylation of ERK1/2 was accelerated by the presence of CCL21 in cultures of IPF/UIP fibroblasts, but the overall magnitude of ERK1/2 activation by this chemokine appeared to be modest, particularly in comparison to the phosphorylation changes evoked in MAPK kinase $1 / 2$ and p90RSK. An explanation for this modest CCL21-induced change in ERK 1/2 phosphorylation is not forthcoming, but examination of its specific role is limited by the lack of specific pharmacological inhibitors of ERK 1/2. To date, the phosphorylation of p90RSK has been shown to be completely dependent upon the actions of ERK $1 / 2$, but it is possible that the action of some other novel kinase may account for p90RSK activation in IPF/UIP fibroblasts. At present, it has been shown that phosphorylation of MAPK kinase 1/2, ERK $1 / 2$ and p90RSK was dependent, in part, upon G-protein activation since PTX inhibited the phosphorylation of these kinases. Accordingly, PTX inhibited CCL21-dependent proliferation and migration of IPF/UIP fibroblasts. The present siRNA experiments provided further evidence that CCL21 activated CCR7 through a CCR7-specific siRNA, which inhibited activation of the ERK $1 / 2$ pathway in IPF/UIP fibroblasts. The advent of specific inhibitors of MAPK kinase 1/2, ERK $1 / 2$ and p90RSK would facilitate further examination of the individual contribution of these kinases in the synthetic, proliferative and migratory changes induced by CCL21 in IPF/ UIP fibroblasts.

In summary, it has been demonstrated that primary human fibroblasts derived from idiopathic pulmonary fibrosis/usual interstitial pneumonia surgical lung biopsy specimens express functional CC chemokine receptor 7. Activation of CC chemokine receptor 7 by its ligands, particularly CC chemokine ligand 21, induced migration, proliferation and chemokine synthesis in idiopathic pulmonary fibrosis/usual interstitial pneumonia fibroblasts. CC chemokine ligand-21induced activation via CC chemokine receptor 7 was G-protein dependent, and involved the activation of the extracellular signal-regulated kinase $1 / 2$ mitogen-activated protein kinase pathway. Given these data and other evidence that targeting 
a)
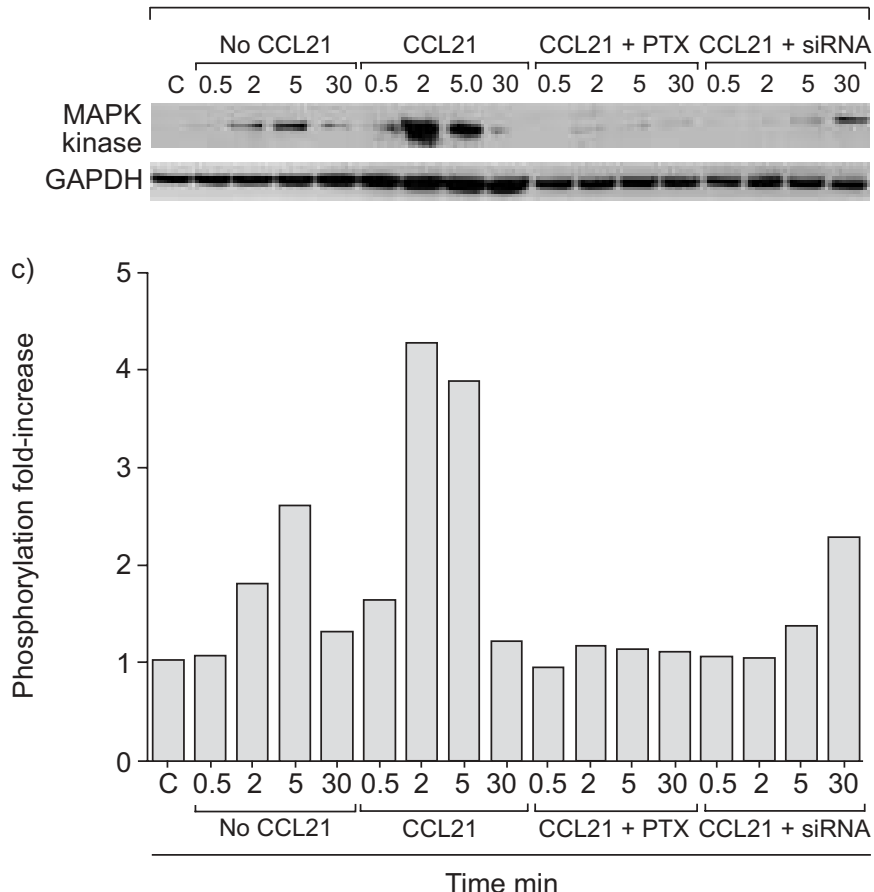

e)

Time $\min$

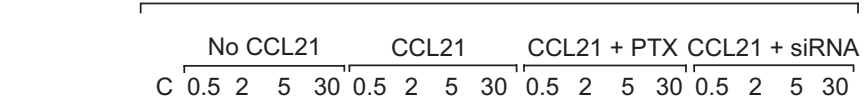
p90RSK - - - - - GAPDH

f)
0
0
0
0
$\frac{0}{0}$
$\frac{1}{1}$
$\frac{1}{0}$
$\frac{0}{0}$
$\frac{1}{0}$
$\frac{0}{\pi}$
$\frac{1}{2}$
$\frac{0}{0}$
$\frac{0}{0}$
0
$\frac{0}{0}$

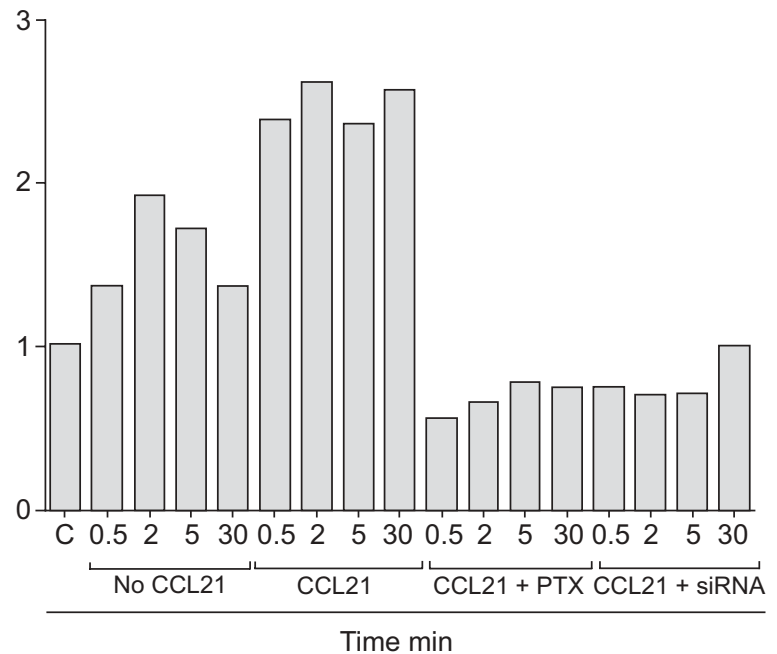

CC chemokine ligand 21 inhibits experimental glomerular [41] and hepatic [42] scarring, it is conceivable that CC chemokine receptor 7 represents a novel target in idiopathic pulmonary fibrosis/usual interstitial pneumonia. Accordingly, studies are underway in the present authors' laboratory (Dept of Pathology, University of Michigan Medical School) to determine the in vivo role of CC chemokine receptor 7 during pulmonary fibrotic responses induced by introduction of b)

Time $\min$

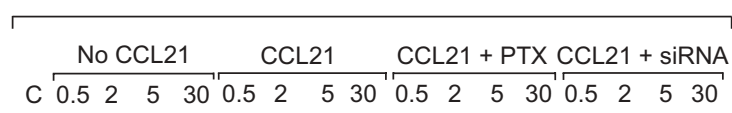

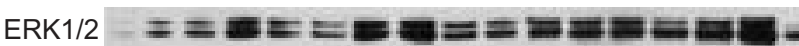

GAPDH

d)

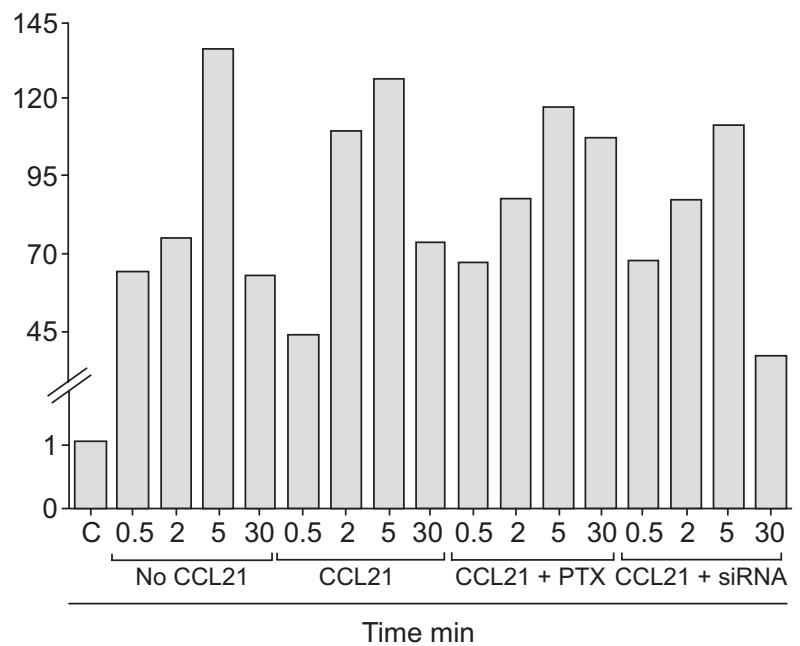

FIGURE 8. - Effects of pertussis toxin (PTX) and small interfering RNA (siRNA) on: a, c) mitogen-activated protein kinase (MAPK) kinase 1/2; b, d) extracellular signal-regulated kinase (ERK) 1/2; and e, f) ribosomal S6 kinase (90 kDa; p90RSK) phosphorylation. Cells were pre-treated with either $200 \mathrm{ng} \cdot \mathrm{mL}^{-1}$ PTX or $50 \mathrm{nM} \mathrm{CC}$ chemokine receptor (CCR) 7 siRNA before being treated with Dulbecco's modified Eagle medium containing $0.5 \%$ foetal bovine serum alone or in combination with $10 \mathrm{ng} \cdot \mathrm{mL}^{-1} \mathrm{CC}$ chemokine ligand $(C C L)$ 21. $a, b, e)$ Western blots, and $c, d, f)$ increase in phosphorylation compared with untreated fibroblasts. Each photographic film was exposed for $30 \mathrm{~s}$. The degree of increase in phosphorylation was determined by normalisation to reduced glyceraldehye-3-phosphate dehydrogenase (GAPDH) levels and then comparison between treated and untreated fibroblasts. The results are representative of three separate experiments. MAPK kinase 1/2 phosphorylation was successfully knocked down by both PTX and CCR7 siRNA. Both PTX and CCR7 siRNA abrogated the CCL21 effects on ERK $1 / 2$ at 2 min and eliminated phosphorylation of p90RSK. C: Untreated fibroblast control.

human idiopathic interstitial pneumonia fibroblasts into severe combined immunodeficiency syndrome mice.

\section{REFERENCES}

1 American Thoracic Society, European Respiratory Society. American Thoracic Society/European Respiratory Society international multidisciplinary consensus classification of 
the idiopathic interstitial pneumonias. Am J Respir Crit Care Med 2002; 165: 277-304.

2 Zisman DA, Keane MP, Belperio JA, Strieter RM, Lynch JP 3rd. Pulmonary fibrosis. Methods Mol Med 2005; 117: 3-44.

3 Raghu G, Weycker D, Edelsberg J, Bradford WZ, Oster G. Incidence and prevalence of idiopathic pulmonary fibrosis. Am J Respir Crit Care Med 2006; 174: 810-816.

4 Flaherty KR, Toews GB, Lynch JP 3rd, et al. Steroids in idiopathic pulmonary fibrosis: a prospective assessment of adverse reactions, response to therapy, and survival. Am J Med 2001; 110: 278-282.

5 Travis WD, Matsui K, Moss J, Ferrans VJ. Idiopathic nonspecific interstitial pneumonia: prognostic significance of cellular and fibrosing patterns: survival comparison with usual interstitial pneumonia and desquamative interstitial pneumonia. Am J Surg Pathol 2000; 24: 19-33.

6 Pardo A, Gibson K, Cisneros J, et al. Up-regulation and profibrotic role of osteopontin in human idiopathic pulmonary fibrosis. PLoS Med 2005; 2: e251.

7 Selman M, Pardo A, Barrera L, et al. Gene expression profiles distinguish idiopathic pulmonary fibrosis from hypersensitivity pneumonitis. Am J Respir Crit Care Med 2006; 173: 188-198.

8 Choi ES, Jakubzick C, Carpenter KJ, et al. Enhanced monocyte chemoattractant protein-3/CC chemokine ligand-7 in usual interstitial pneumonia. Am J Respir Crit Care Med 2004; 170: 508-515.

9 Jakubzick C, Choi ES, Carpenter KJ, et al. Human pulmonary fibroblasts exhibit altered interleukin-4 and interleukin-13 receptor subunit expression in idiopathic interstitial pneumonia. Am J Pathol 2004; 164: 1989-2001.

10 Agostini C, Gurrieri C. Chemokine/cytokine cocktail in idiopathic pulmonary fibrosis. Proc Am Thorac Soc 2006; 3: 357-363.

11 Zlotnik A, Yoshie O. Chemokines: a new classification system and their role in immunity. Immunity 2000; 12: 121-127.

12 Choi ES, Pierce EM, Jakubzick C, et al. Focal interstitial CC chemokine receptor 7 (CCR7) expression in idiopathic interstitial pneumonia. J Clin Pathol 2006; 59: 28-39.

13 Baggiolini M. Chemokines and leukocyte traffic. Nature 1998; 392: 565-568.

14 Abe R, Donnelly SC, Peng T, Bucala R, Metz CN. Peripheral blood fibrocytes: differentiation pathway and migration to wound sites. J Immunol 2001; 166: 7556-7562.

15 Hashimoto N, Jin H, Liu T, Chensue SW, Phan SH. Bone marrow-derived progenitor cells in pulmonary fibrosis. J Clin Invest 2004; 113: 243-252.

16 Muller A, Homey B, Soto H, et al. Involvement of chemokine receptors in breast cancer metastasis. Nature 2001; 410: 50-56.

17 Pierce EM, Carpenter KJ, Jakubzick C, et al. CCL21 induces phosphorylation of ERK in usual interstitial pneumonia fibroblasts. J Immunol 2006; 176: 44.

18 Hogaboam CM, Carpenter KJ, Evanoff H, Kunkel SL. Approaches to evaluation of fibrogenic pathways in surgical lung biopsy specimens. Methods Mol Med 2005; 117: 209-221.

19 Jakubzick C, Choi ES, Kunkel SL, Joshi BH, Puri RK, Hogaboam CM. Impact of interleukin-13 responsiveness on the synthetic and proliferative properties of Th1- and Th2-type pulmonary granuloma fibroblasts. Am J Pathol 2003; 162: 1475-1486.
20 Burstein E, Ganesh L, Dick RD, et al. A novel role for XIAP in copper homeostasis through regulation of MURR1. EMBO J 2004; 23: 244-254.

21 Qiagen. Gene Globe. Gene-specific products for human, mouse, rat and other species. https://www1.qiagen.com/ GeneGlobe/Default.aspx. Date last accessed: April 13, 2007.

22 Rudd BD, Burstein E, Duckett CS, Li X, Lukacs NW. Differential role for TLR3 in respiratory syncytial virusinduced chemokine expression. J Virol 2005; 79: 3350-3357.

23 Sozzani S, Allavena P, D'Amico G, et al. Differential regulation of chemokine receptors during dendritic cell maturation: a model for their trafficking properties. J Immunol 1998; 161: 1083-1086.

24 Murakami T, Cardones AR, Hwang ST. Chemokine receptors and melanoma metastasis. J Dermatol Sci 2004; 36: 71-78.

25 White ES, Atrasz RG, Hu B, et al. Negative regulation of myofibroblast differentiation by phosphatase and tensin homologue deleted on chromosome ten. Am J Respir Crit Care Med 2006; 173: 112-121.

26 Kim EA, Lee KS, Johkoh T, et al. Interstitial lung diseases associated with collagen vascular diseases: radiologic and histopathologic findings. Radiographics 2002; 22: Spec No. 22, S151-S165.

27 Cui CH, Adachi T, Oyamada $\mathrm{H}$, et al. The role of mitogenactivated protein kinases in eotaxin-induced cytokine production from bronchial epithelial cells. Am J Respir Cell Mol Biol 2002; 27: 329-335.

28 Atamas SP, Luzina IG, Choi J, et al. Pulmonary and activation-regulated chemokine stimulates collagen production in lung fibroblasts. Am J Respir Cell Mol Biol 2003; 29: 743-749.

29 Keane MP, Arenberg DA, Lynch JP 3rd, et al. The CXC chemokines, IL-8 and IP-10, regulate angiogenic activity in idiopathic pulmonary fibrosis. J Immunol 1997; 159: 1437-1443.

30 Prasse A, Pechkovsky DV, Toews GB, et al. A vicious circle of alveolar macrophages and fibroblasts perpetuates pulmonary fibrosis via CCL18. Am J Respir Crit Care Med 2006; 173: 781-792.

31 Puxeddu I, Bader R, Piliponsky AM, Reich R, LeviSchaffer F, Berkman N. The CC chemokine eotaxin/ CCL11 has a selective profibrogenic effect on human lung fibroblasts. J Allergy Clin Immunol 2006; 117: 103-110.

$32 \mathrm{Kim} \mathrm{CH}$, Broxmeyer HE. SLC/exodus2/6Ckine/TCA4 induces chemotaxis of hematopoietic progenitor cells: differential activity of ligands of CCR7, CXCR3, or CXCR4 in chemotaxis vs. suppression of progenitor proliferation. J Leukoc Biol 1999; 66: 455-461.

33 Moore BB, Kolodsick JE, Thannickal VJ, et al. CCR2mediated recruitment of fibrocytes to the alveolar space after fibrotic injury. Am J Pathol 2005; 166: 675-684.

34 Phillips RJ, Burdick MD, Hong K, et al. Circulating fibrocytes traffic to the lungs in response to CXCL12 and mediate fibrosis. J Clin Invest 2004; 114: 438-446.

35 Moore MA. The role of chemoattraction in cancer metastases. Bioessays 2001; 23: 674-676.

36 Lukacs NW, Hogaboam C, Campbell E, Kunkel SL. Chemokines: function, regulation and alteration of inflammatory responses. Chem Immunol 1999; 72: 102-120. 
37 Kohout TA, Nicholas SL, Perry SJ, Reinhart G, Junger S, Struthers RS. Differential desensitization, receptor phosphorylation, $\beta$-arrestin recruitment, and ERK1/2 activation by the two endogenous ligands for the CC chemokine receptor 7. J Biol Chem 2004; 279: 23214-23222.

38 Bardi G, Lipp M, Baggiolini M, Loetscher P. The T cell chemokine receptor CCR7 is internalized on stimulation with ELC, but not with SLC. Eur J Immunol 2001; 31: 3291-3297.

39 Yoshida K, Kuwano K, Hagimoto N, et al. MAP kinase activation and apoptosis in lung tissues from patients with idiopathic pulmonary fibrosis. J Pathol 2002; 198: 388-396.
40 Yang LV, Radu CG, Wang L, Riedinger M, Witte ON. Giindependent macrophage chemotaxis to lysophosphatidylcholine via the immunoregulatory GPCR G2A. Blood 2005; 105: 1127-1134.

41 Sanchez-Sanchez N, Riol-Blanco L, de la Rosa G, et al. Chemokine receptor CCR7 induces intracellular signaling that inhibits apoptosis of mature dendritic cells. Blood 2004; 104: 619-625.

42 Bonacchi A, Petrai I, Defranco RM, et al. The chemokine CCL21 modulates lymphocyte recruitment and fibrosis in chronic hepatitis C. Gastroenterology 2003; 125: 1060-1076. 